\title{
Insulin sensitivity is related to the fatty acid composition of serum lipids and skeletal muscle phospholipids in 70-year-old men
}

\author{
B. Vessby, S. Tengblad, H. Lithell \\ Department of Geriatrics, Uppsala University, PO Box 2151, S-750 02 Uppsala, Sweden
}

\begin{abstract}
Summary Recent data indicate that peripheral insulin sensitivity may be influenced by dietary fat quality and skeletal muscle phospholipid fatty acid composition. During a health survey of 70-year-old men insulin sensitivity was measured by the euglycaemic hyperinsulinaemic clamp technique and the fatty acid composition of the serum cholesterol esters was determined $(n=215)$ by gas liquid chromatography. In a subsample the fatty acids of the skeletal muscle phospholipids and triglycerides were determined after fine needle biopsy from $\mathrm{m}$. vastus lateralis $(n=39)$. The peripheral insulin sensitivity was significantly and negatively correlated to the proportion of palmitic $(r=-0.31, p<0.001)$, palmitoleic $(r=-0.25$, $p<0.001)$ and di-homo- $\gamma$-linolenic $(r=-0.33$, $p<0.001)$ acids and positively to the content of linoleic $(r=0.28, p<0.001)$ acid in the serum cholesterol esters. There was an even stronger negative relation-
\end{abstract}

Recent data indicate that peripheral insulin sensitivity may be influenced by dietary fat quality and by skeletal muscle phospholipid fatty acid composition. A high proportion of $n-3$ fatty acids in the food to rats fed high fat diets reduces the risk of developing peripheral insulin resistance $[1,2]$. In humans, a high concentration of long chain polyunsaturated fatty acids in the skeletal muscle phospholipids was associated with an increased insulin sensitivity, suggesting that changes in the fatty acid composition of the cell membranes may modulate the action of insulin [3].

Received: 22 February 1994

and in revised form: 30 May 1994

Corresponding author: Dr. B. Vessby, Department of Geriatrics, Uppsala University, PO Box 2151, S-750 02 Uppsala, Sweden ship to the proportion of palmitic acid in the skeletal muscle phospholipds $(r=-0.45, p<0.004)$. The fatty acid composition was also significantly related to insulin sensitivity in a stepwise multiple regression analysis in the presence of other clinical variables, which were associated with insulin action in univariate analysis. Thus, more than $51 \%$ of the variation of the insulin sensitivity was explained by an equation containing body mass index, serum triglyceride concentration and the content of palmitic acid in the skeletal muscle phospholipids. It is concluded that the fatty acid composition in serum and of the phospholipids of skeletal muscle may influence insulin action in elderly men. [Diabetologia (1994) 37: 1044-1050]

Key words Cholsterol esters, fatty acid composition, insulin sensitivity, palmitic acid, phospholipids, skeletal muscle.
The present study was undertaken to investigate the association between the fatty acid composition of serum cholesterol esters and skeletal muscle phospholipids and triglycerides on the one hand and peripheral insulin sensitivity, as measured by the euglycaemic hyperinsulinaemic clamp technique, on the other. The investigation was performed in 70-yearold men as a part of an ongoing health survey. Also, associations between other clinical characteristics and insulin sensitivity were evaluated.

\section{Subjects and methods}

During a health survey of 70-year-old men in the town of Uppsala, Sweden, clinical characteristics including anthropometric measurements, analyses of lipid and glucose metabolism and 
determinations of the fatty acid composition of serum and skeletal muscle lipids were performed. Also, peripheral insulin sensitivity was measured by the euglycaemic, hyperinsulinaemic clamp technique. The survey was performed as a part of an ongoing prospective study. The participants were earlier studied at ages 50 and 60 . However, on these occasions no measurement of insulin sensitivity was performed.

The composition of the fatty acids of the serum cholesterol esters was determined in all the men who attended the health survey. The present report concerns the first 218 men who were consecutively analysed. Seventy of these men were on antihypertensive medication and 39 had non-insulin-dependent diabetes mellitus. As antihypertensive medication may influence peripheral insulin sensitivity, all analyses were performed twice including and excluding, respectively, all subjects on antihypertensive medication. In addition, the fatty acid compositions of the skeletal muscle phospholipids and triglycerides were determined in a random subsample $(n=39)$ after fine needle biopsy from musculus vastus lateralis. Thirteen of these men were being treated with antihypertensive drugs, the majority using selective $\beta$-adrenergic blockers. Nine men, four of whom had non-insulin-dependent diabetes were being treated with other types of medication. None of the latter were treated with insulin.

Laboratory methods. All subjects were studied in the morning. They were asked to refrain from smoking and had been fasting overnight.

Body mass index was calculated as the body weight $(\mathrm{kg}) \mathrm{di}-$ vided by squared height (in meters). Blood pressure was measured in the supine position on the right arm with a mercury sphygmomanometer after 10-min rest. Systolic and diastolic blood pressures were defined as phase I and V, respectively, according to Korotkoff (to the nearest $\mathrm{mm}$ ).

Cholesterol and triglyceride concentrations were determined in serum and HDL lipid concentrations were determined in the supernatant after precipitation with a sodium phosphotungstate and magnesium chloride solution [4]. Triglyceride and cholesterol concentrations were determined in serum and in HDL by enzymatic methods using BoehringerMannheim (Mannheim, Germany) kits, modified for use in a Multistat III, F/LS apparatus (Instrumentation Laboratories, Lexington, Mass., USA). The coefficients of variation in the assays were 2.7 and $1.7 \%$, respectively. The concentrations of plasma non-esterified fatty acids were determined by an enzymatic colorimetric method using a commercially available kit (Waho Chemicals GmbH, Neuss, Germany) applied for use in the Multistat III centrifugal analyzer.

Blood glucose concentrations were measured by the glucose oxidase assay. Serum insulin was determined by radioimmunoassay (Phadeseph Insulin RIA 100, Pharmacia Diagnostics AB, Uppsala, Sweden). Insulin sensitivity was evaluated by the euglycaemic hyperinsulinaemic clamp technique according to De Fronzo [5] as earlier described [6] in 215 men. The rate of infusion of insulin was $56 \mathrm{mU} / \mathrm{m}^{2}$ per min in all subjects resulting in a mean plasma insulin concentration of about $100 \mathrm{mU} / \mathrm{l}$. The mean steady-state plasma glucose concentration in the clamp was $5.2 \mathrm{mmol} / \mathrm{l}$. The index of sensitivity of peripheral insulin ( $\left.\mathrm{M} / \mathrm{I}_{60-120}\right)$ was calculated by dividing the amount of glucose taken up by the mean insulin concentration attained during the last 60 min of the clamp.

For determination of the fatty acid composition $5 \mathrm{ml}$ of methanol was added to $1 \mathrm{ml}$ of plasma. Chloroform $(10 \mathrm{ml})$ containing $0.005 \%$ butylated hydroxytoluene as an antioxidant, was then added followed by $15 \mathrm{ml}$ of $0.2 \mathrm{~mol} / \mathrm{l}$ sodium dihydrogen phosphate $\left(\mathrm{NaH}_{2} \mathrm{DO}_{4}\right)$ [7]. After thorough mixing the extract was left at $+4^{\circ} \mathrm{C}$ for $1-4$ days. The chloroform phase was evaporated to dryness under nitrogen and the lipid residue was dissolved in chloroform. The lipid esters (triglycerides, cholesterol esters and phospholipiods) were separated by thin-layer chromatography as previously described [8] and transmethylated at $60^{\circ} \mathrm{C}$ overnight after addition of $2 \mathrm{ml} 5 \%$ $\mathrm{H}_{2} \mathrm{SO}_{4}$ in methanol. The methyl esters were extracted into $3 \mathrm{ml}$ of petroleum ether (b.p. $40-60^{\circ} \mathrm{C}$ ) containing $0.005 \%$ butylated hydroxytolvene after adding $1.5 \mathrm{ml}$ distilled water. The phases were separated after thorough mixing and centrifugation at $1500 \times g$ for $10 \mathrm{~min}$. The petroleum ether phase was pipetted off and the solvent was evaporated under nitrogen. The methyl esters were then redissolved in $1 \mathrm{ml}$ Uvasol, grade hexane.

The fatty acid methyl esters were separated by gas-liquid chromatography on a 25-m WCOT (wall-coated open tubular) glass capillary column coated with SLP OV-351 (QUADREX), with helium as carrier gas. A Hewlett-Packard system consisting of GLC 5890, integrator 3396 and autosampler $7671 \mathrm{~A}$ was used. The fatty acids were identified by comparing retention times with those of Nu Check Prep (Elysian, Minn., USA) fatty acid methyl ester standard and PUFA-mix No. 2 (animal source, 22:5 n-6, 22:5 n-3) (Supelco, Bellefonte, Pa., USA). The coefficients of variation for the determinations of the proportions of fatty acids in the serum cholesterol esters were less than $3 \%$ for all the fatty acids which were significantly related to insulin sensitivity.

In a subsample of the men $(n=39)$ a fine needle biopsy was performed from the musculus vastus lateralis. Small pieces of skeletal muscle tissue $(15-30 \mathrm{mg})$ were homogenized in $1 \mathrm{ml}$ of physological saline by a Kinematica Polytron PT 3000 homogenizer at $30.000 \mathrm{rpm}$ for $15 \mathrm{~s}$ on ice. The homogenized muscle tissue was extracted overnight by a solvent system containing $5 \mathrm{ml}$ methanol, $10 \mathrm{ml}$ chloroform containing $0.005 \%$ butylated hydroxytolvene and $15 \mathrm{ml} 0.2 \mathrm{~mol} / / \mathrm{NaH}_{2} \mathrm{PO}_{4}$. The chloroform phase was evaporated to dryness under nitrogen after which the lipid esters were separated by thin-layer chromatography as described above, transmethylated and analysed by gas-liquid chromatography.

\section{Statistical analysis}

The proportions of individual fatty acids in the serum cholesterol esters and in the skeletal muscle phospholipids and triglycerides were expressed as a percentage of the total fatty acids identified. All results are expressed as the mean \pm SD. The relations between variables were analysed by linear correlation and by stepwise multiple regression analysis using the SAS analysis system program [9].

\section{Results}

Clinical characteristics and relation to insulin sensitivity. Some of the clinical characteristics of the men investigated are shown in Table 1 . The relationships between the clinical characteristics and the peripheral insulin sensitivity, as measured by the euglycaemic clamp technique, are also shown. There were highly significant negative correlations between insulin sensitivity on the one hand and body mass index, serum triglycerides, serum free fatty acid and fasting blood glucose concentrations on the other. There were weaker inverse relationships between the systolic 
Table 1. Relationships between peripheral insulin sensitivity and clinical characteristics in 70-year-old men

\begin{tabular}{|c|c|c|c|}
\hline & $\begin{array}{l}\mathrm{x} \pm \mathrm{SD} \\
(n=215)\end{array}$ & $\begin{array}{l}\text { Linear } \\
\text { correlation } \\
\text { coefficient }\end{array}$ & $p$-value \\
\hline $\begin{array}{l}\text { Body mass index } \\
\left(\mathrm{kg} / \mathrm{m}^{2}\right)\end{array}$ & $26.1 \pm 3.5$ & -0.59 & $<0.001$ \\
\hline Waist-hip ratio & $0.94 \pm 0.05$ & -0.44 & $<0.001$ \\
\hline $\begin{array}{l}\text { S-cholesterol } \\
(\mathrm{mmol} / \mathrm{l})\end{array}$ & $5.75 \pm 0.95$ & -0.01 & NS \\
\hline $\begin{array}{l}\text { S-triglycerides } \\
(\mathrm{mmol} / 1)\end{array}$ & $1.45 \pm 0.90$ & -0.39 & $<0.001$ \\
\hline $\begin{array}{l}\text { S-HDL cholesterol } \\
(\mathrm{mmol} / \mathrm{l})\end{array}$ & $1.25 \pm 0.34$ & +0.39 & $<0.001$ \\
\hline $\begin{array}{l}\text { Non-esterified } \\
\text { fatty acids (mmol/l) }\end{array}$ & $0.50 \pm 0.18$ & -0.26 & $<0.001$ \\
\hline $\begin{array}{l}\text { Fb-glucose } \\
(\mathrm{mmol} / \mathrm{l})\end{array}$ & $5.8 \pm 1.5$ & -0.38 & $<0.001$ \\
\hline $\begin{array}{l}\text { F-s-insulin } \\
(\mathrm{mU} / \mathrm{l})\end{array}$ & $10.9 \pm 6.9$ & -0.59 & $<0.001$ \\
\hline $\begin{array}{l}\text { Systolic blood } \\
\text { pressure }(\mathrm{mm} \mathrm{Hg})\end{array}$ & $150 \pm 17$ & -0.21 & 0.002 \\
\hline $\begin{array}{l}\text { Diastolic blood } \\
\text { pressure }(\mathrm{mm} \mathrm{Hg})\end{array}$ & $86 \pm 9$ & -0.18 & 0.009 \\
\hline
\end{tabular}

Table 2. Fatty acid composition (\%) of serum cholesterol esters and skeletal muscle phospholipids and triglycerides in 70year-old men $\bar{X} \pm \mathrm{SD}$ )

\begin{tabular}{|c|c|c|c|}
\hline \multirow[t]{2}{*}{ Fatty acid } & \multirow{2}{*}{$\begin{array}{l}\text { Serum chole- } \\
\text { sterol esters }\end{array}$} & \multicolumn{2}{|l|}{ Skeletal muscle } \\
\hline & & $\begin{array}{l}\text { phospholipids } \\
(n=218)\end{array}$ & $\begin{array}{l}\text { triglycerides } \\
(n=39)\end{array}$ \\
\hline $16: 0$ & $11.9 \pm 1.0$ & $22.5 \pm 3.0$ & $25.2 \pm 2.1$ \\
\hline $16: 1 \mathrm{n}-7$ & $4.0 \pm 1.1$ & $1.1 \pm 0.3$ & $6.3 \pm 1.4$ \\
\hline $18: 0$ & $1.0 \pm 0.2$ & $13.6 \pm 1.1$ & $5.9 \pm 1.1$ \\
\hline $18: 1 \mathrm{n}-9$ & $20.8 \pm 2.6$ & $13.9 \pm 1.1$ & $47.5 \pm 1.8$ \\
\hline $18: 2 n-6$ & $51.8 \pm 5.1$ & $32.5 \pm 3.7$ & $12.4 \pm 2.3$ \\
\hline $18: 3 n-6$ & $0.7 \pm 0.3$ & $0.5 \pm 0.2$ & $0.4 \pm 0.8$ \\
\hline $18: 3 n-3$ & $0.8 \pm 0.2$ & $0.7 \pm 0.3$ & $1.1 \pm 0.3$ \\
\hline $20: 3 n-6$ & $0.7 \pm 0.1$ & $1.1 \pm 0.2$ & $0.2 \pm 0.1$ \\
\hline $20: 4 n-6$ & $5.8 \pm 1.1$ & $10.0 \pm 1.6$ & $0.4 \pm 0.1$ \\
\hline $20: 5 n-3$ & $1.7 \pm 0.6$ & $1.6 \pm 0.5$ & $0.2 \pm 0.2$ \\
\hline $22: 4 n-6$ & - & - & $0.2 \pm 0.1$ \\
\hline $22: 5 n-3$ & - & $1.6 \pm 0.3$ & $0.4 \pm 0.1$ \\
\hline $22: 6 n-3$ & $1.0 \pm 0.3$ & $3.0 \pm 0.9$ & $0.6 \pm 0.2$ \\
\hline
\end{tabular}

and diastolic blood pressure and insulin sensitivity with a significant positive relationship to the serum HDL-cholesterol concentration. There was no significant correlation with the serum cholesterol concentrations. It is notable that the relationship between insulin sensitivity and body mass index was stronger than that between insulin sensitivity and waist-hip ratio in this population.

If all the men on antihypertensive treatment $(n=70)$ were excluded the relationships described in Table 1 remained essentially unaltered. The only difference was that the weak negative relationships be-

\section{B. Vessby et al.: Fatty acid composition and insulin sensitivity}

Table 3. Significant relationships between peripheral insulin sensitivity and fatty acid composition in serum (S) cholesterol esters and skeletal muscle (SM) phospholipids and triglycerides, respectively

\begin{tabular}{|c|c|c|}
\hline & $\begin{array}{l}\text { Linear correlation } \\
\text { coefficient }\end{array}$ & $p$-value \\
\hline \multicolumn{3}{|l|}{$\begin{array}{l}\text { S-cholesterol esters } \\
(n=215)\end{array}$} \\
\hline $16: 0$ & -0.31 & $<0.001$ \\
\hline $16: 1 \mathrm{n}-7$ & -0.25 & 0.002 \\
\hline $18: 2 n-6$ & +0.28 & $<0.001$ \\
\hline $18: 3 n-6$ & -0.16 & 0.019 \\
\hline $20: 3 n-6$ & -0.33 & $<0.001$ \\
\hline $20: 4 n-6$ & -0.16 & 0.022 \\
\hline \multicolumn{3}{|l|}{$\begin{array}{l}\text { SM-phospholipids } \\
(n=38)^{\mathrm{a}}\end{array}$} \\
\hline $16: 0$ & -0.45 & 0.004 \\
\hline \multicolumn{3}{|l|}{$\begin{array}{l}\text { SM-triglycerides } \\
(n=39)\end{array}$} \\
\hline $16: 0$ & -0.33 & 0.044 \\
\hline
\end{tabular}

a Analysis of the skeletal muscle phospholipids lacking in one subject

tween systolic and diastolic blood pressure, respectively, and insulin sensitivity were no longer significant.

Relationships between the serum cholesterol ester fatty acid composition and the fatty acid composition of the skeletal muscle lipids and insulin sensitivity. The fatty acid composition of the serum cholesterol esters and the skeletal muscle phospholipids and triglycerides is shown in Table 2.

The relationships between the peripheral insulin sensitivity and the fatty acid composition of the serum cholesterol esters and skeletal muscle lipids were evaluated (Table 3 ). There were significant negative relationships between insulin sensitivity and the proportions of palmitic (16:0), palmitoleic $(16: 1$ $\mathrm{n}-7)$ and di-homo- $\gamma$-linolenic acids (20:3 n-6) in the serum cholesterol esters while there was a positive correlation to the relative linoleic acid content $(18: 2$ $n-6)$. The strongest relationship was between the proportion of di-homo- $\gamma$-linolenic acid and insulin sensitivity (Fig. 1). When all subjects on antihypertensive medication were excluded from the analyses the major correlations between the serum cholesterol esters and peripheral insulin sensitivity remained essentially unchanged.

The only significant relationship between the fatty acid composition of the skeletal muscle phospholipids and triglycerides and the peripheral insulin sensitivity was a significant negative relationship between the palmitic acid content in the skeletal muscle lipids and the insulin sensitivity (Table 3, Fig.2). There was a positive correlation between the proportion of palmitic acid in the phospholipids and the triglycerides in the skeletal muscle $(r=0.40, p=0.013)$. 


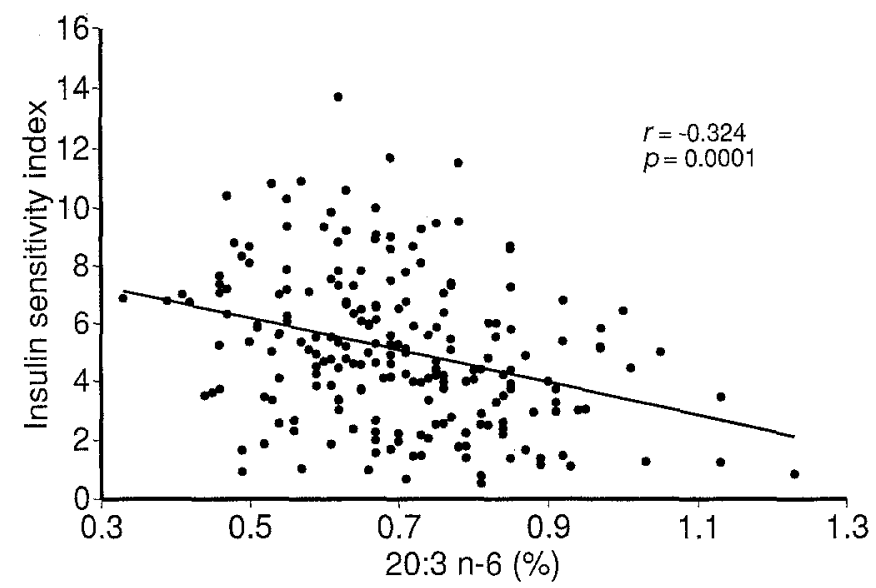

Fig. 1. Relationship between the proportion of di-homo- $\gamma$-linolenic acid (20:3 n-6) in the serum cholesterol esters and the insulin sensitivity index in 70-year-old men $(n=215)$

The correlation between the content of palmitic acid in the skeletal muscle and peripheral insulin sensitivity increased $(r=-0.55, p=0.005)$ after exclusion of the 13 men who were on antihypertensive treatment while the relationship to the proportion of palmitic acid in the skeletal muscle triglycerides weakened $(r=-0.12, \mathrm{NS})$.

There were no significant relationships between the proportion of linoleic acid in the skeletal muscle lipids and insulin sensitivity. Nor were there any significant relationships between the long chain polyunsaturated fatty acids of the n-6 or the n-3 family in serum or in the skeletal muscle lipids, respectively, and the insulin sensitivity. The relationship between the proportion of palmitic acid in the skeletal muscle phospholipids and in the serum cholesterol esters was not statistically significant $(r=0.26$, NS), while there was a significant positive relationship between the proportion of palmitic acid of the skeletal muscle triglycerides and that of the serum cholesterol esters $(r=0.56, p<0.001)$. Also, the relative content of palmitic acid in the skeletal muscle triglycerides was strongly positively correlated to the proportion of palmitoleic acid in the cholesterol esters in serum $(r=0.61, p<0.001)$ and negatively to linoleic acid $(r=-0.56, p<0.001)$.

There were significant positive relationships between the proportion of linoleic acid in the serum cholesterol esters and that of the skeletal muscle phospholipids and triglycerides, respectively (Table 4). There were also significant correlations between the proportions of $\gamma$-linolenic $(18: 3 \mathrm{n}-6)$, dihomo- $\gamma$-linolenic and docosahexaenoic (22:6 n-3) acids in the serum cholesterol esters and in the skeletal muscle lipids.

Insulin sensitivity as a function of the fatty acid composition and other clinical characteristics. When the proportions of the fatty acids of the serum cholester-

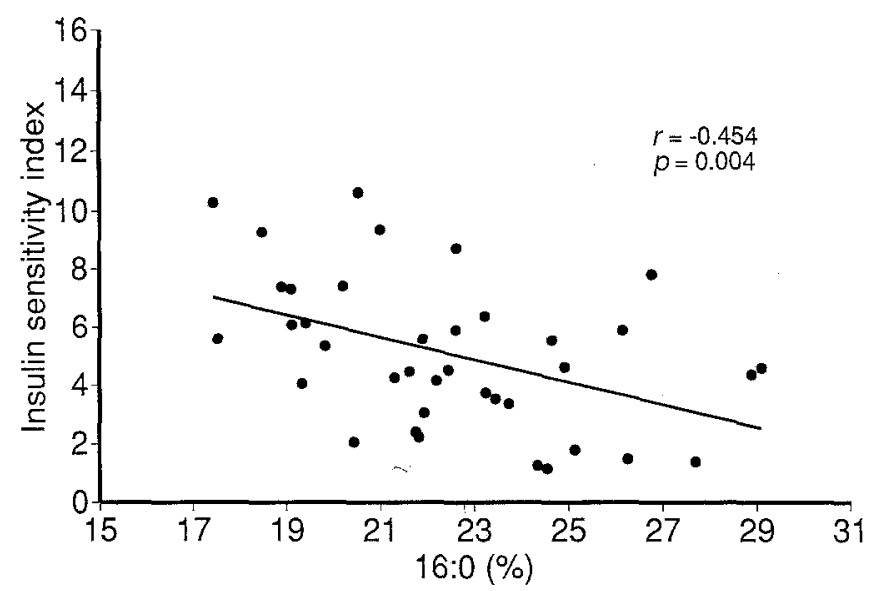

Fig. 2. Relationship between the proportion of palmitic acid $(16: 0)$ in the skeletal muscle phospholipids and the insulin sensitivity index in 70-year-old men $(n=38)$

Table 4. Relationships (linear correlation coefficients) between the proportions of fatty acids in the serum cholesterol esters and those of the corresponding fatty acid in the skeletal muscle phospholipids and triglycerides, respectively

\begin{tabular}{lll}
\hline Fatty acid & $\begin{array}{l}\text { Relationships between } \\
\text { skeletal muscle phospho- } \\
\text { lipids and serum choles- } \\
\text { terol esters }(n=38)\end{array}$ & $\begin{array}{l}\text { Relationships between } \\
\text { skeletal muscle trigly- } \\
\text { cerides and serum cho- } \\
\text { lesterol esters }(n=39)\end{array}$ \\
\hline $16: 0$ & NS & $0.56^{\mathrm{c}}$ \\
$16: 1$ & $\mathrm{NS}$ & $\mathrm{NS}$ \\
$18: 0$ & $\mathrm{NS}$ & $\mathrm{NS}$ \\
$18: 1$ & $\mathrm{NS}$ & $\mathrm{NS}$ \\
$18: 2 \mathrm{n}-6$ & $0.42^{\mathrm{a}}$ & $0.75^{\mathrm{c}}$ \\
$18: 3 \mathrm{n}-6$ & $\mathrm{NS}$ & $\mathrm{NS}$ \\
$18: 3 \mathrm{n}-3$ & $\mathrm{NS}$ & $\mathrm{NS}$ \\
$20: 3 \mathrm{n}-6$ & $0.53^{\mathrm{b}}$ & $\mathrm{NS}$ \\
$20: 4 \mathrm{n}-6$ & $0.42^{\mathrm{a}}$ & $0.40^{\mathrm{a}}$ \\
$20: 5 \mathrm{n}-3$ & $\mathrm{NS}$ & $\mathrm{NS}$ \\
$22: 6 \mathrm{n}-3$ & $0.49^{\mathrm{b}}$ & $0.48^{\mathrm{b}}$ \\
\hline $\mathrm{a}, \mathrm{b}, \mathrm{c} p<0.05,0.01$ and 0.001, respectively
\end{tabular}

ol esters were tested as explaining variables in a multiple regression analysis with insulin sensitivity as the dependent variable, di-homo- $\gamma$-linolenic acid and palmitic acid came out as significant independent variables together explaining $18 \%$ of the variation of insulin sensitivity. Excluding all the subjects on antihypertensive medication did not change the results. If the proportion of palmitic acid in the skeletal muscle lipid esters was also introduced as an explaining variable, $27 \%$ of the variation of insulin sensitivity was explained by the variations of di-homo- $\gamma$-linolenic acid in the cholesterol esters and of palmitic acid in the skeletal muscle phospholipids. One third $(n=13)$ of the men who underwent a skeletal muscle biopsy were on antihypertensive treatment. Stepwise regression analysis with insulin sensitivity as the dependent variable was also repeated after exclusion of these men. Only the proportion of palmitic acid re- 
1048

Table 5. The variation of the peripheral insulin sensitivity in 70 -year-old men $(n=38)$ as measured by the euglycaemic clamp technique, when analysed by stepwise forward regression analysis, was explained by:

\begin{tabular}{llll}
\hline & $\beta$-coefficient & $p$-value & Partial $R^{2}$ \\
\hline $\begin{array}{l}\text { BMI } \\
\begin{array}{l}\text { S-triglyceride } \\
\text { concentrations }\end{array}\end{array}$ & -0.286 & 0.002 & $33 \%$ \\
$\begin{array}{l}\text { Palmitic acid (16:0) } \\
\begin{array}{l}\text { in skeletal muscle } \\
\text { phospholipids }\end{array}\end{array}$ & -1.096 & 0.018 & $11 \%$ \\
Total model $R^{2}$ & -0.239 & 0.032 & $7 \%$ \\
\hline
\end{tabular}

Table 6. The variation of peripheral insulin sensitivity in 70year-old men without antihypertensive treatment $(n=25)$, when analysed by stepwise forward regression analysis, was explained by:

\begin{tabular}{llll}
\hline & $\beta$-coefficient & $p$-value & Partial $R^{2}$ \\
\hline $\begin{array}{l}\text { S-triglyceride } \\
\text { concentrations }\end{array}$ & -1.703 & 0.002 & $30 \%$ \\
$\begin{array}{l}\text { Palmitc acid (16:0) } \\
\begin{array}{l}\text { in skeletal muscle } \\
\text { phospholipids }\end{array}\end{array}$ & -0.462 & 0.003 & $24 \%$ \\
Total model $R^{2}$ & & & $54 \%$ \\
\hline
\end{tabular}

mained as a significant independent variable explaining $23 \%$ of the variation of insulin sensitivity.

When different constellations of clinical variables which were significantly related to insulin sensitivity (Table 1) and fatty acids were tested together as explaining variables, the best prediction of the variation of insulin sensitivity was achieved in a stepwise forward regression analysis by an equation including body mass index, serum triglyceride concentrations and the proportion of palmitic acid in the skeletal muscle phospholipids (Table 5). Together these three variables explained $51 \%$ of the variation of the insulin sensitivity. If the four patients with non-insulin-dependent diabetes were excluded this figure increased to $56 \%$. If the 13 men on antihypertensive medication were excluded the best prediction of the variation of insulin sensitivity was achieved by introducing serum triglycerides and the proportion of palmitic acid in the skeletal muscle phospholipids as independent variables. Together they explained $54 \%$ of the variation of the insulin sensitivity. Adding body mass index to the equation did not improve the model further (Table 6).

\section{Discussion}

The present study was performed to elucidate the relationships between clinical characteristics, fatty acid composition in serum cholesterol esters and skeletal

\section{B. Vessby et al.: Fatty acid composition and insulin sensitivity}

muscle lipids and peripheral insulin sensitivity as measured by the euglycaemic hyperinsulinaemic clamp technique in 70-year-old men. There were significant relationships between several of the clinical characteristics and insulin sensitivity. An equation including body mass index, serum triglycerides and the proportion of palmitic acid in the skeletal muscle phospholipids could explain more than half of the variation in insulin sensitivity.

There were highly significant relationships between the fatty acid composition of the serum cholesterol esters and the peripheral insulin sensitivity with the strongest relationships to the proportions of dihomo- $\gamma$-linolenic acid, palmitic acid, linoleic acid and palmitoleic acid. An increasing proportion of palmitic, palmitoleic and di-homo- $\gamma$-linolenic acids in the serum cholesterol esters with increasing degree of glucose intolerance, with lower levels of linoleic acid in diabetic subjects than in the subjects with impaired or normal glucose tolerance, was found by Salomaa et al. [10] in a population-based study. It was suggested that the fatty acid composition of plasma and membrane lipids may have a role in insulin resistance and blood glucose regulation.

The fatty acid composition of the serum cholesterol esters reflects the average dietary fat quality during the preceding 2-3 weeks $[11,12]$. Significant positive relationships between the content of different fatty acids in the diet, as estimated from dietary surveys, and the proportion of fatty acids in the serum cholesterol esters have been repeatedly demonstrated $[12-14]$. When changing the dietary fat quality, keeping all other nutrients unchanged, there is a gradual change of the serum cholesterol ester and phospholipid fatty acid composition during the following weeks reaching an apparant new steady state after approximately 3 weeks [11].

A shift of dietary fat quality from a diet containing a high proportion of saturated fat to one high in linoleic acid causes a shift of the serum lipid fatty acid composition with a reduction of the proportions of palmitic acid and palmitoleic acids and an increased proportion of linoleic acid $[11,12]$ resulting in a fatty acid pattern compatible with an improved peripheral insulin sensitivity.

In the present study of 70-year-old men the fatty acid composition of the skeletal muscle phospholipids and triglycerides was determined in a random subsample. A strong negative relationship was discovered between the proportion of palmitic acid in the skeletal muscle phospholipids and insulin sensitivity. Also, in the presence of the most powerful clinical predictors of insulin sensitivity the fatty acid composition of the skeletal muscle phospholipids still contributed as a significant explaining variable. This was true even after exclusion of men on antihypertensive treatment or with diabetes. This indicates that the fatty acid composition of the skeletal muscle phospholi- 
pids may be of significance for, and influence, insulin action, also in elderly men. Whether the proportion of palmitic acid in the skeletal muscle phospholipids is directly related to the dietary fat quality, or whether it mainly reflects a high amount of intramuscular lipids, which may be partly endogenously synthesized, is at present not possible to establish.

Significant relationships between the fatty acid composition of the serum phospholipids and insulin sensitivity in healthy men has earlier been demonstrated by Pelikanova et al. [15]. Borkman and coworkers [3] showed a direct relationship between the fatty acid composition in the skeletal muscle phospholipids and different measures of insulin action in healthy young men and in patients with coronary heart disease. In their study, as well as in earlier experimental studies in rats performed by the same group [1,2], the main relationships between insulin sensitivity and fatty acid composition of the skeletal muscle lipids were seen between the proportions of long chain polyunsaturated fatty acids and insulin sensitivity. However, also in these studies there were significant negative relationships to the palmitic acid content.

Is it not known whether a change of dietary fat composition will actually alter insulin sensitivity in humans. Most studies have failed to show any change in peripheral glucose elimination after supplementation with n-3 fatty acids in non-insulin-dependent diabetes [16-18] but an improvement was reported by Popp-Snijders et al. [19]. Fasching et al. [20] fed n-3 fatty acids to overweight subjects with impaired glucose tolerance and reported an increased glucose disposal rate during the 1-mU but not during the 10 -mU insulin clamp period. Recent data by Uusitupa et al. [21] suggest that the dietary fatty acid composition may also affect glucose tolerance in healthy subjects.

In our study, we could not detect any significant relationships between the proportions of $n-3$ fatty acids, the sum of long chain fatty acids or the ratio between 20:4 and 20:3 and insulin sensitivity. In contrast strong positive relationships were detected in the study by Borkman and co-workers [3]. The reason for this discrepancy between our studies is at present not clear. It may be due to differences in methodology or of the age of the participants or both. Factors relating to aging, e.g. muscle capillarity, may reduce or obscure other relationships which are more apparent in younger people. It may also be due to differences in the fatty acid composition of the Scandinavian and Australian populations, presumably reflecting divergent dietary habits. The relative proportion of long chain n-3 fatty acids in the elderly men in Scandinavia $(6.2 \%)$ was higher than that in the Australian populations ( 4.9 and $4.5 \%$, respectively). One explanation for the lack of significant relationships between the proportions of n-3 fatty acids in the skeletal mus- cle phospholipids and insulin sensitivity in the Swedish study may be the higher average proportions of $\mathrm{n}-3$ fatty acids. In experimental studies, the content of n-3 fatty acids in the diet, as well as in the tissues, has been shown to be critical for the maintenance of good insulin sensitivity [2].

It can be speculated that the importance of dietary fat quality on insulin sensitivity may be even more important than what is indicated by the statistical analyses performed here. Thus, there were for example highly significant relationships between body mass index and serum triglyceride concentrations, respectively, on the one hand and cholesterol ester fatty acids in the serum on the other. It seems more probable that the fatty acid composition, as mirroring the dietary fat quality, would influence the body weight and the serum lipid levels, and thereby indirectly also the insulin sensitivity, rather than the reverse.

In conclusion the results of the present study suggest that the fatty acid composition of the serum cholesterol esters and of the phospholipids of skeletal muscle, presumably at least partly reflecting dietary fat quality, may influence insulin action in elderly men. This is in line with earlier observational $[3,10]$ and experimental $[1,2]$ studies indicating that the type of dietary fat is of importance for the development of glucose intolerance and non-insulin-dependent diabetes. The coupling between high-fat diets and insulin resistance has recently been discussed by Storlien et al. [22]. They have suggested two potential mechanisms which may explain the development of insulin resistance after feeding of certain types of dietary fat, one via glucose lipid interactions, as suggested by the glucose/fatty acid cycle of Randle et al. [23], and the second via changes in membrane lipid fatty acid composition consistent with the "leaky membrane" hypothesis of Else and Hulbert [24].

Acknowledgements. We thank Rawya Mohsen for performing the statistical analyses. Financial support for this study was provided by grants from the Swedish Margarine Industrial Association for Nutritional-Physiological Research, the Gustav V 80 years Foundation and the Swedish Medical Research Foundation (grant No 5446).

\section{References}

1. Storlien LH, Kraegen EW, Chisholm DJ, Ford GL, Bruce DG, Pascoe WS (1987) Fish oil prevents insulin resistance induced by high-fat feeding in rats. Science 237:885 -888

2. Storlien LH, Jenkins AB, Chisholm DJ, Pascoe WS, Khouri S, Kraegen EW (1991) Influence of dietary fat composition on development of insulin resistance in rats. Relation to muscle triglyceride and w-3 fatty acids in muscle phospholipid. Diabetes 40:280-289

3. Borkman M, Storlien LH, Pan DA, Jenkins AB, Chisholm DJ, Campbell LB (1993) The relationship between insulin sensitivity and the fatty acid composition of skeletal-muscle phospholipids. N Engl J Med 328:238-244 
4. Seigler L, Wu WT (1981) Separation of serum high-density lipoprotein for cholesterol determination: ultracentrifugation vs. precipitation with sodium phosphotungstate and magnesium chloride. Clin Chem 27:834-841

5. DeFronzo RA, Tobin JD, Andres R (1979) Glucose clamp technique: a method for quantifying insulin secretion and resistance. Am J Physiol 237:E214-E223

6. Pollare T, Lithell H, Selinus I, Berne C (1988) Application of prazosin is associated with an increase of insulin sensitivity in obese patients with hypertension. Diabetologia 31:415-420

7. Boberg M, Croon I-B, Gustafsson I-B, Vessby B (1985) Platelet fatty acid composition in relation to fatty acid composition in plasma and to serum lipoprotein lipids in healthy subjects with special reference to the linoleic acid pathway. Clin Sci 68:581-587

8. Boberg J (1966) Separation of labelled plasma and tissue lipids by thin layer chromatography - A quantitative methodological study. Clin Chim Acta 14:325-334

9. SAS Institute Inc. SAS user's guide: statistics. Cary, NC: SAS Institute, 1982

10. Salomaa V, Ahola I, Tuomilehto J, Aro A, Pietinen P, Korhonen PJ, Pentilä I (1990) Fatty acid composition of serum cholesterol esters in different degrees of glucose intolerance. Metabolism 39:1285-1291

11. Vessby B, Gustafsson IB, Boberg J, Karlström B, Lithell H, Werner I (1980) Substituting polyunsaturated for saturated fat as a single change in a Swedish diet: effects on serum lipoprotein metabolism and glucose tolerance in patients with hyperlipoproteinemia. Eur J Clin Invest 120:193-202

12. Glatz JFC, Soffers AEMF, Katan MB (1987) Fatty acid composition of serum cholesteryl esters and erythocyte membranes as indicators of linoleic acid intake in man. Am J Clin Nutr 49:269-276

13. De Backer G, De Craene I, Rosseneu M, Vercaemst R, Kornitzer M (1989) Relationships between serum cholesteryl ester composition, dietary habits and coronary risk factors in middle-aged men. Atherosclerosis 78:237-243

14. v. Houwelingen AC, Kester ADM, Kromhout D, Hornstra $\mathrm{G}$ (1989) Comparison between habitual intake of polyunsaturated fatty acids and their concentrations in serum lipid fractions. Europ J Clin Nutr 43:11-20
15. Pelikanova T, Kohout M, Valet J, Base J, Kazdova L (1989) Insulin-secretion and insulin action are related to the serum phospholipid fatty acid pattern of healthy men. Metabolism 38:188-192

16. Glauber HP, Wallace K, Griver K, Brechtel G (1988) Adverse metabolic effects of omega- 3 fatty acids in non-insulin-dependent diabetes mellitus. Ann Intern Med 108:663668

17. Vessby B, Karlström B, Boberg M, Lithell H, Berne C (1992) Polyunsaturated fatty acids may impair blood glucose control in type 2 diabetic patients. Diabet Med 9:126133

18. Annuzzi G, Rivellese A, Capaldo B, DiMarino L, Lovine C, Marotta G, Riccardi G (1991) A controlled study on the effects of n-3 fatty acids on lipid and glucose metabolism in non-insulin-dependent diabetes patients. Atherosclerosis $87: 65-73$

19. Popp-Snijders C, Schouten JA, Heine RJ, van der Meer J, van der Veen EA (1987) Dietary supplementation of omega-3 polyunsaturated fatty acids improves insulin sensitivity in non-insulin-dependent diabetes. Diabetes Res 4:6573

20. Fasching P, Ratheiser K, Waldhäusl W, Rohac M, Osterrode W, Nowotny P, Vierhapper H (1991) Metabolic effects of fish-oil supplementation in patients with impaired glucose tolerance. Diabetes 40:583-588

21. Uusitupa M, Schwab U, Mäkimattila S et al. (1994) Effects of two high-fat diets with different fatty acid compositions on glucose and lipid metabolism in healthy young women. Am J Clin Nutr 59: 1310-1316

22. Storlien LH, Pan DA, Kriketos AD, Baur LA (1993) High fat diet-induced insulin resistance. Lessons and implications from animal studies. In: I Klimes, BV Howard, LH Storlien, E Sebökova (eds) Dietary lipids and insulin action. Annals N Y Acad Sci 683:82-90

23. Randle PJ, Garland PB, Hales CN, Newsholme EA (1963) The glucose fatty acid cycle, its role in insulin sensitivity and the metabolic disturbances of diabetes mellitus. Lancet I:785-789

24. Else PC, Hulbert AJ (1987) Evolution of mammalian endothermic metabolism: "Leaky" membranes as a source of heat. Am J Physiol 253:R1-R7 